\title{
An Experimental Investigation of the Flow Structure on a Face Mannequin With / Without a Face Shield
}

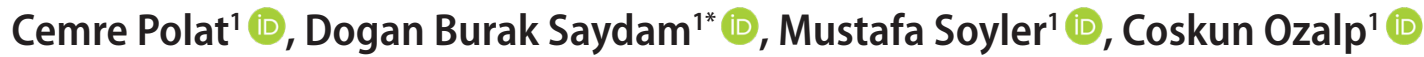 \\ 'Osmaniye Korkut Ata University, Faculty of Engineering, Department of Energy Systems Engineering, Osmaniye, Turkey.
}

\begin{abstract}
This study investigated experimentally the flow regime with a face shield on a face mannequin placed at different distances ( $\mathrm{L}=50 \mathrm{~cm}$ and $\mathrm{L}=150 \mathrm{~cm}$ to source of flow), i.e., perpendicular to the channel or at an angle of $10^{\circ}$, through the PIV (Particle Imaging Velocimetry) method along with the dye experiments, based on which the face shield and dye injector were positioned to conduct the PIV tests. As a result of the experiments, instantaneous velocity vectors and velocity magnitude data were obtained, and the flow structure around the face shield was examined in detail. The study revealed that the flow released through the respiratory tract hit the face and eye area of the mannequin in the experiments performed without using a face shield, yet, with the face shield, the flow that emerged while talking at a close distance was directed from the lower part of the face shield towards the neck and jaw but protected the face and eye area compared to the case without a face shield. It was observed that the flow lost its energy when it first left the flow source, and the velocity vectors were directed down the neck area. Positioning the mannequin at an angle of $10^{\circ}$ turned out to be less protective than positioning it perpendicular to the channel, due to the flow being directed from the jaw to the mouth area with the effect of the angle.
\end{abstract}

Keywords: Social Distance, Face Shield, Flow Characteristic, Covid-19, PIV

\section{INTRODUCTION}

It is stated by health authorities that COVID-19 is rapidly transmitted by respiratory tract or contact [1]. In recent years, it has been observed that viral spread has dispersed groups of infectious particles [2]. Biological particles from bacteria, viruses and fungi can be found in the air that is breathing [3]. Droplets carrying infectious virus are ejected by an infected person because of activities such as breathing, coughing, speaking, and sneezing, and these particles, which can be carried, can be made to surfaces or suspended in the air, can be inhaled or taken into the body by people who are not adequately protected or who do not pay much attention to hand hygiene $[4,5]$. Considering this situation, infectious disease outbreaks are likely to spread in places where there is a high human population in public spaces, office spaces, lecture halls, public transportation [6]. The typical breathing processes of an individual can be classified as breathing-i.e., inhaling and exhaling- talking, laughing, coughing, and sneezing. Human respiration changes according to the respiration rate. Depending on the intensity of breathing, talking, coughing and sneezing, an air flow occurs through the respiratory tract, within which particles of various sizes exist. Particles can lose their initial high velocity due to air friction after the first moment they leave the source, and it is, therefore, crucial to understand the movement of particles caused by coughing, sneezing, talking, and breathing to control the spread of infectious respiratory diseases [7-9].

The use of personal protective equipment (PPE) is essential to reduce or prevent people and especially healthcare workers from the risk of getting infected [10]. In particular, healthcare-related infection risks can be encountered in healthcare facilities around the world [11]. Considering this situation, PPE designed and recommended to be used especially for healthcare workers acts as a shield between healthcare workers and viruses [12]. It is also known that using a protective face mask is effective in reducing the risk of contagion due to coronavirus particles transmitted by droplets and aerosols [13]. Surgical masks have been a part of healthcare workers' clothing for over 100 years. Surgical masks are developed to filter and prevent the spread of microorganisms in the mouth [14]. Not only masks, but also gloves, goggles, face shields and aprons are used extensively as PPE in infections where the risk of transmission is high [15]. Especially healthcare professionals are in the high-risk group as they work in close proximity to the face of patients during the treatment of Covid-19 [16]. Healthcare profes- 
sionals use such equipment as face shields as a physical barrier to wear on the head to prevent direct contact with the droplets during some droplet-producing procedures such as intubation and respiratory physiotherapy [17]. This kind of equipment is designed to reduce the risk of direct exposure to infective droplets through splash [18].

There are limited studies in the literature on the behavior of personal protective equipment under a flow. However, it is possible to see many different experimental and numerical studies in which breathing, speaking, coughing, and sneezing reactions are simulated from the starting point whereas the flow movements of these situations are examined under different conditions in an environment [19-26]. In the study by Licinia et al. [21], the researchers examined the velocity field around the mannequin under two different ambient temperatures and body postures, and the effects of different types of clothing, chair design and table positioning on the airflow properties of the breathing zone for a sitting mannequin. Badeau et al. [22], examined the impacts of microorganism transport in confined spaces during coughing process in relation to computational fluid dynamics of particles and flow-field behavior in a designed square chamber. Using Computational Fluid Dynamics (CFD), Ge et al. [23], conducted a numerical study to analyze the inhalation of particles by a mannequin in a closed space with a ventilation system. Richmond-Bryant [24], who used the computational fluid dynamics simulations, examined the characteristics of the dimensional velocity and concentration profiles of airflow, which could cause healthcare workers to be exposed to a pathogenic substance in the air in the infection isolation room (AIIR). Tang et al. [25], researchers have visualized the sneezing and breathing states of healthy volunteers using a real-time shadow graph display technique. Clark and Golf [26], examined the interaction of airborne dispersion of photogenic particles and droplets with ventilation in an operating room environment.

As can be seen in the literature review, many researchers examined the flow structure of the distribution of the air flow and the number of particles, especially because of talking or breathing, in different simulations. Understanding the motion of a liquid or a molecule within the flow is as important as the motion of fluid on bodies. For this, in this study, contrary to the literature, the flow structure around a bluff body (face shield) was investigated experimentally, independent of particle density and particle amount. The main purpose of this study is to examine the flow structure around the face shield used as personal protective equipment. This study conducted two different experiments in which the distances between the two mannequin heads were $50 \mathrm{~cm}$ and $150 \mathrm{~cm}$, respectively, to determine the flow characteristics of the face shield. First the dye and then the particles for PIV experiments were sent by an adjustable pump from the first mannequin to the second. Later, PIV experiments were conducted by placing the second mannequin's head with the face shield at an angle of $10^{\circ}$. This study aims to pose an original example for scientific research or engineering applications and designs to be carried out in this respect.

\section{MATERIALS AND METHOD}

The experiments were conducted in an open water channel, shown in Figure 1, in the Advanced Fluid Mechanics Laboratory at Osmaniye Korkut Ata University. The water channel includes two axial pumps with rotation control, two collecting pools, and one flow regulator in a honeycomb pattern with grids, in addition to the field of view made of plexiglass. The water tunnel was manufactured as fully sealed. The tunnel is $1.8 \mathrm{~m}$ high and $4 \mathrm{~m}$ wide with the maximum length of $15 \mathrm{~m}$. The test chamber in the water tunnel is of 6 $\mathrm{m}$ long, with $80 \times 80 \mathrm{~cm}$ of a cross-sectional top opening. The length of the channel is $80 \mathrm{~cm}$, and its depth is $100 \mathrm{~cm}$. A maximum of $80 \mathrm{~cm}$ of water can be filled. The speed ranges in the channel are between $10 \mathrm{~mm} / \mathrm{s}-500 \mathrm{~mm} / \mathrm{s}$. Prior to entering the test chamber, the flow passes through a sedimentation tank, a honeycomb, and a constriction at a ratio of 2:1. The change in the speed profile with height in the middle of the test chamber is less than $2 \%$. The turbulence density in the middle of the test chamber at a speed of $0.3 \mathrm{~m} / \mathrm{s}$ was calculated below $2 \%$.

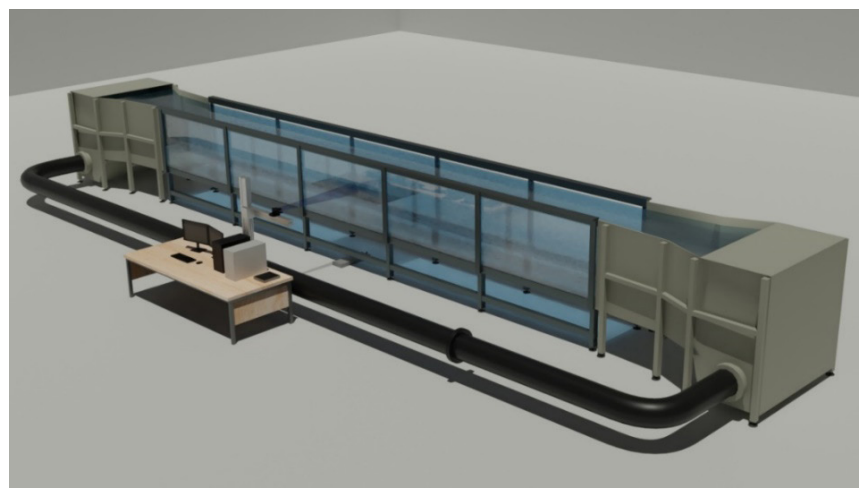

Figure 1. Technical Drawing of the Closed-circuit, Open Water Channel [31]

The study first examined the flow structure through dye experiments to have preliminary information about the structure, and to position the experimental equipment correctly. In the dye experiments, snapshots were taken with a Canon brand, EOS M50 (24MP) model digital mirrorless camera at a resolution of $1280 * 720$ pixels in the form of 100 frames per second and of at least 66 seconds (the time corresponding to the acquisition of 1000 sets of instant data in PIV experiments), after which the images were analyzed and visuals representing the flow structure were formed for each experiment. Rhodamine $6 \mathrm{G}$ dye in powder form was mixed with water so that it would glow under laser light and allow detailed observation of the flow structure. A certain amount of salt was added into the dye and water mixture to obtain a solution with increased density compared to water with the aim of modelling the particles and droplets in water, which come out of the mouth while talking approximately. During the experiments, the dye was injected into the pump by designing. In this way, not only flow visualization 
was achieved but also necessary information was obtained about the flow structure before PIV experiments. As a result of the dye experiments, the mannequins and the speech simulation were positioned to start the PIV experiments. Upon collecting the experimental data in the flow plane, the distorted or bad vectors were removed, with the data filtered and arranged. Images of silver coated particles used in PIV were used to calculate vector displacements. Since the particle images had random functions, the resulting correlation functions had random components with the possibility of producing slightly inaccurate measurements that needed to be removed before the data set could be used. After calculating the velocity field, the distorted vectors (less than about $3 \%$ ) were removed with the CleanVec program and the field of view was scaled according to the real flow area [27]. The PIV system consists of a basic software that performs the analysis to obtain velocity vectors by providing the connection between laser, camera, synchronizer subsystems, a computer, and the system. It involves a pair of Nd:YAG laser sources, each with a power of $120 \mathrm{~mJ}$, a high-resolution digital camera, laser sources and a synchronizer as well as various optical elements that enable the digital camera to work together. The digital camera can shoot 15 snapshots per second with a resolution of $1600 \times 1186$ pixels. In addition, the camera was equipped with a $50 \mathrm{~mm}$ f1.8 aperture lens. Spherical silver-plated particles of 20-micron diameter with a density higher than that of water were scattered into the flow so that it would collapse under the effect of gravity in still water. The measurement area was illuminated by a laser beam approximately $2 \mathrm{~mm}$ thick. The time interval between laser pulses was chosen as 0.066 seconds. It was concluded that the errors in velocity measurements made using the PIV technique were less than $2 \%$ [28].

The experiments involved a human head mannequin and a face shield model, which is used extensively by healthcare and community care professionals in the fight against the pandemic, in order to represent reality. Figure 2 presents a schematic representation of the mannequin head model in the flow area, and the visual of the face shield placed on the model, as well as a second mannequin where the speech simulation was performed. Figure 2-(a) represents the schematic representation of the mannequin head models placed perpendicular to the channel, whereas Figure 2-(b) shows those at an angle of $10^{\circ}$ to the channel. We investigated the impact on the flow structure in relation to the distances between the two models positioned at two different spots as $\mathrm{L}=50 \mathrm{~cm}$ and $\mathrm{L}=150 \mathrm{~cm}$, and the positioning of the mannequin model with the face shield placed perpendicular to the channel and at an angle of $10^{\circ}$. The cameras optical sensor uses Charge-Coupled Device (CCD) technology for converting light info collected from lens to digital image data. In Figure 3, there is an image of the CCD sensor camera used in the PIV study and the head mannequin with a face shield, around which the flow structure was examined. PIV studies in the literature have shown that the average flow velocity during speech can be $3.1 \mathrm{~m} / \mathrm{s}$ in air $[29,30]$. In the study, Reynolds' Law of Similarity was used and the Reynolds number for water was found to be $R e \cong 35500$. In this direction, taking into account the studies in the literature, water containing dye and particulates was injected into the channel through an injector out of a reservoir at a constant velocity of $\cong 0.31 \mathrm{~m} / \mathrm{s}$ for water and containing silver-coated particles. Figure 4 presents the image with the viewing area of the examined mannequin model.

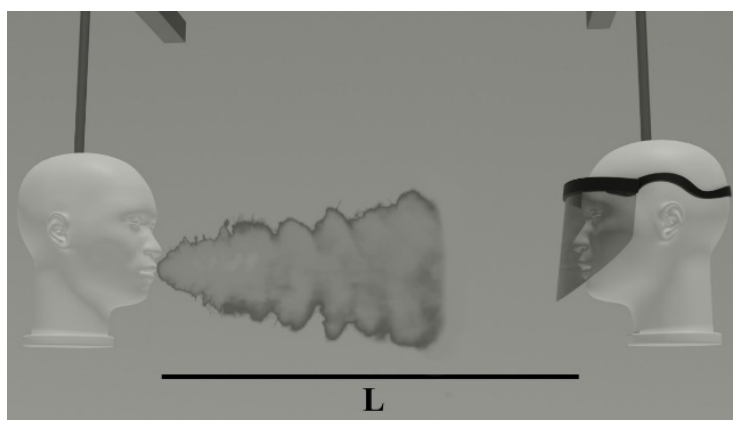

(a)

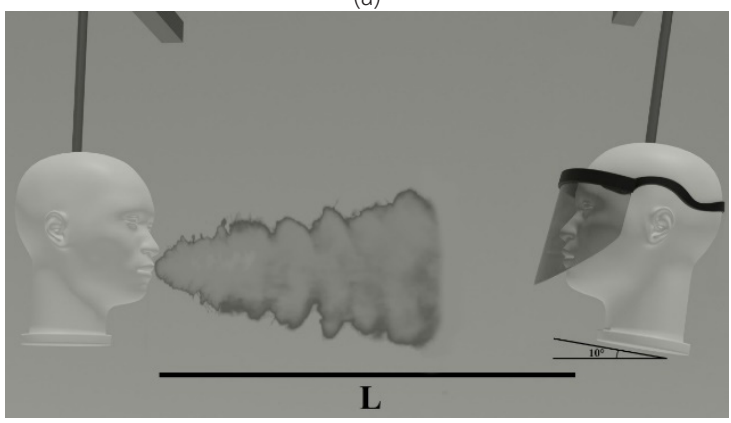

(b)

Figure 2. The image of the mannequin head models within the water channel, a) perpendicular to the channel and b) placed at an angle of $10^{\circ}$ to the channel

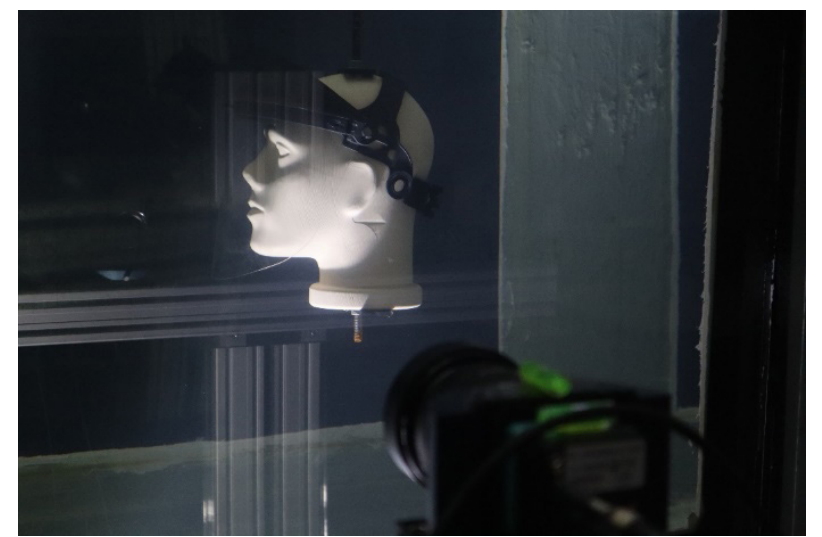

Figure 3. The image of the mannequin head model and the CCD sensor camera located in the water channel where the experiments were conducted

\section{RESULTS AND DISCUSSION}

Figures 4, 5 and 6 present the images of the dye experiments on the mannequin model performed using the PIV technique in the open surface water channel in the Advanced Fluid Mechanics Laboratory at Osmaniye Korkut Ata University. Snapshots were selected from among the dye experiments within a certain time interval to reach the results. Figure 5 shows how the dye was sprayed on the head model from a distance of $\mathrm{L}=50 \mathrm{~cm}$ without using face shield, and 
the movement of the dye on the mannequin surface. It is clearly seen that the dye hitting the face directly progresses towards the mannequin's nose and eyes $(t=2.320 \mathrm{~s})$. Figure 5 presents the images of the dye experiment conducted at certain time intervals with the dye spraying apparatus positioned at a distance of $\mathrm{L}=50 \mathrm{~cm}$ for the trial where face shield was used. Since the time elapsed between the first time the dye came out of the injector and the contact with the face shield was short due to the short distance between the two objects, the dye directly hit the face shield surface $(t=1.40 \mathrm{~s})$ and moved from the lower area of the face shield towards the neck of the mannequin $(t=2.332 \mathrm{~s})$ after hitting. Compared to the experiment without one, the face shield directed the flow coming to the face away from the nose and eye area in the first place. However, it is seen that the flow of the dye injected at very close range $(\mathrm{L}=50 \mathrm{~cm})$ can be carried up from the lower surface of the face shield towards the neck, even up to the jaw. Figure 6 shows the images of the dye experiments conducted with the dye spraying apparatus positioned at $\mathrm{L}=150 \mathrm{~cm}$ away from the face shield. The dye sprayed from a further distance than $\mathrm{L}=50 \mathrm{~cm}(\mathrm{~L}=150 \mathrm{~cm})$ seemed to lose its motion energy in the flow until it reached the face shield and moved away from the neck area $(t=20 \mathrm{~s}$ and $t=24 s$ ) without creating a flow movement from the lower part of the face shield to the jaw. It is also evident that the use of PPE has a preventive effect at first contact. The

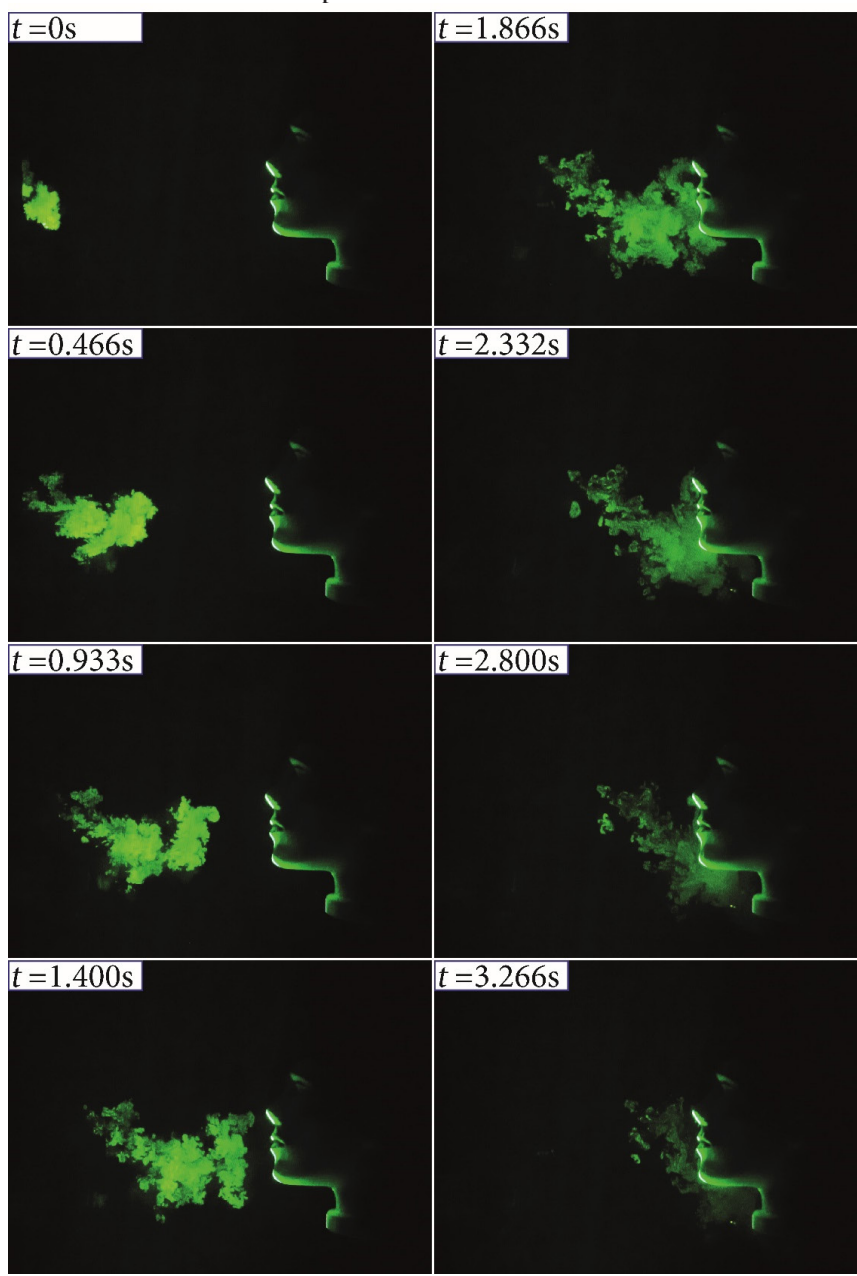

Figure 4. The snapshots of the dye experiments performed on the mannequin without a face shield at different time intervals $(50 \mathrm{~cm})$ study examined the flow structure through the PIV method to make a spraying process, like the act of speech, reach the face shield from different distances $(\mathrm{L}=50 \mathrm{~cm}$ and $\mathrm{L}=150 \mathrm{~cm}$ ) as well as determining the flow characteristics on the face shield. The highest and lowest values of velocity magnitude, which is the resultant flow velocity, on the contour were 0 $\mathrm{m} / \mathrm{s}$ and $0.31 \mathrm{~m} / \mathrm{s}$, respectively, whereas the increase interval was $\Delta \mathrm{V}=0.026 \mathrm{~m} / \mathrm{s}$. PIV experiments were also conducted in that speed range at different $\mathrm{L}$ distances and different angles.

Figures 7-11 present the snapshots obtained at different times $(1 / 15 \mathrm{~s})$ as a result of the PIV experiments. The time interval is taken as 4 seconds for both frames. The mannequin inside the channel was examined when it was perpendicular $\left(0^{\circ}\right)$ and when positioned at an angle of $10^{\circ}$ to the channel. Figure 7 shows the snapshots of the face shield surface taken flow simulation at $\mathrm{L}=50 \mathrm{~cm}$. The figures show the velocity vectors hitting the shield surface with high speed. Such vectors reach the neck of the mannequin model with the impact of the flow. The images for the values of $t=1.866 \mathrm{~s}, \mathrm{t}=2.232 \mathrm{~s}$ and $t=2.800$ s represent that the flow was directed by hitting the lower tip of the face shield. In Figure 8, there are snapshots of the face shield taken flow simulation at $\mathrm{L}=150 \mathrm{~cm}$. It is seen that the velocity vectors that emerged as a result of the performed from a farther position compared to the $\mathrm{L}=50 \mathrm{~cm}$ lost their energy and weakened. Consequently, the

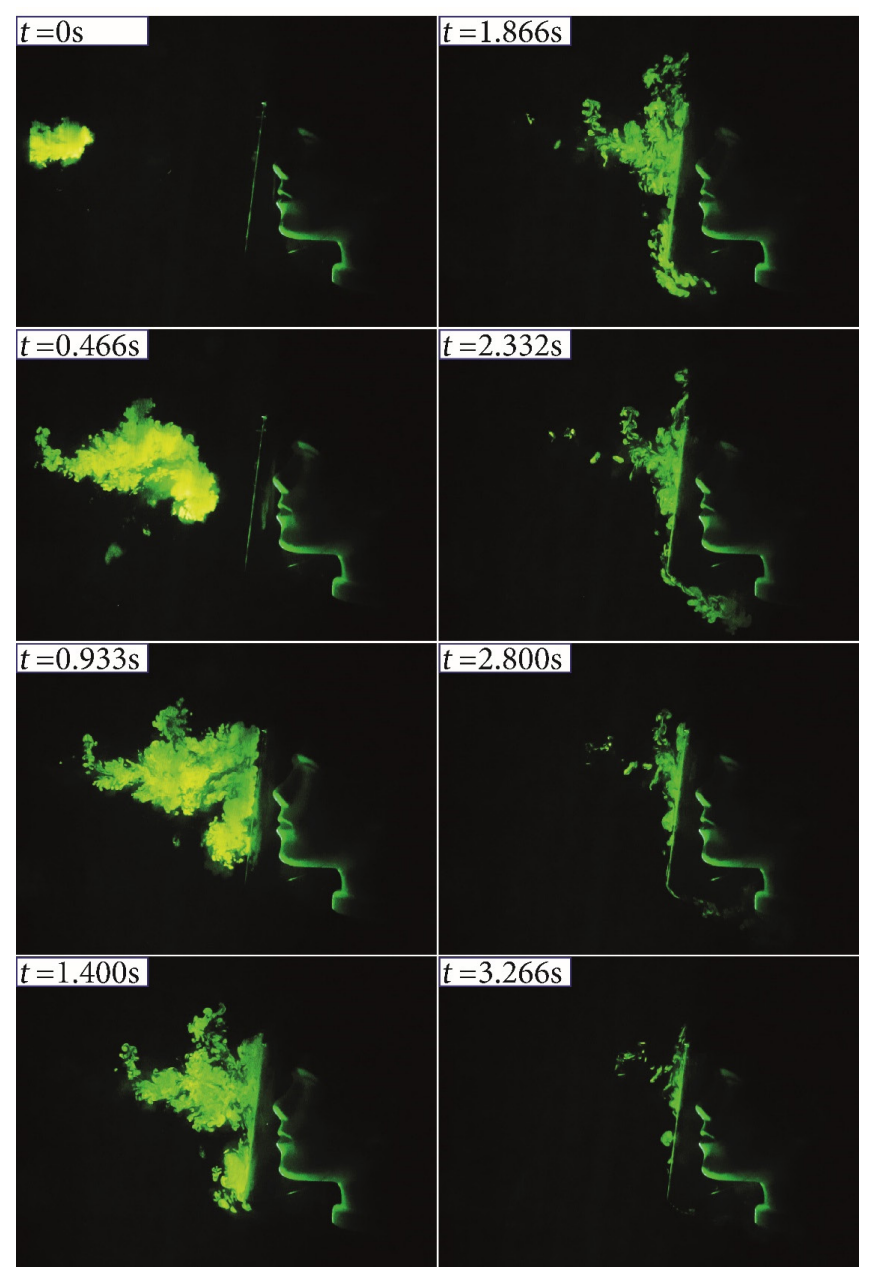

Figure 5. The snapshots of the dye experiments performed on the mannequin with a face shield at different time intervals $(50 \mathrm{~cm})$ 


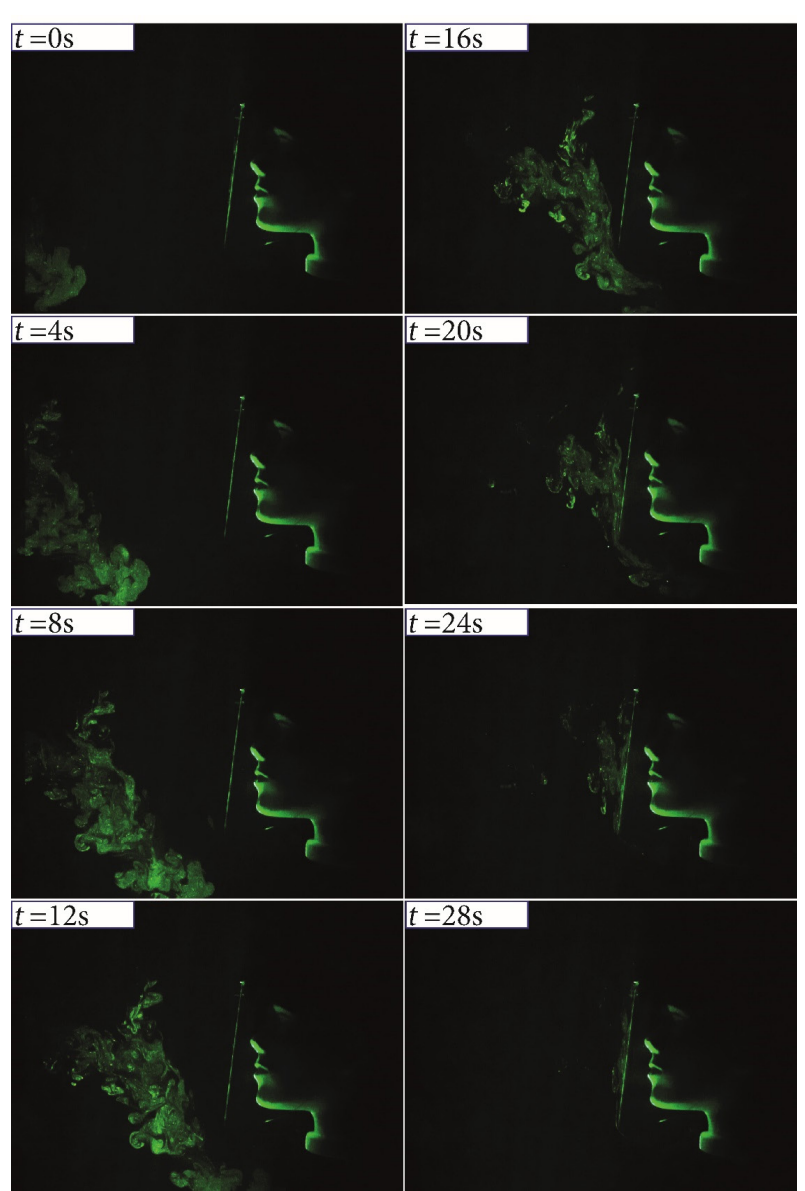

Figure 6. The snapshots of the dye experiments performed on the mannequin with a face shield at different time intervals $(150 \mathrm{~cm})$

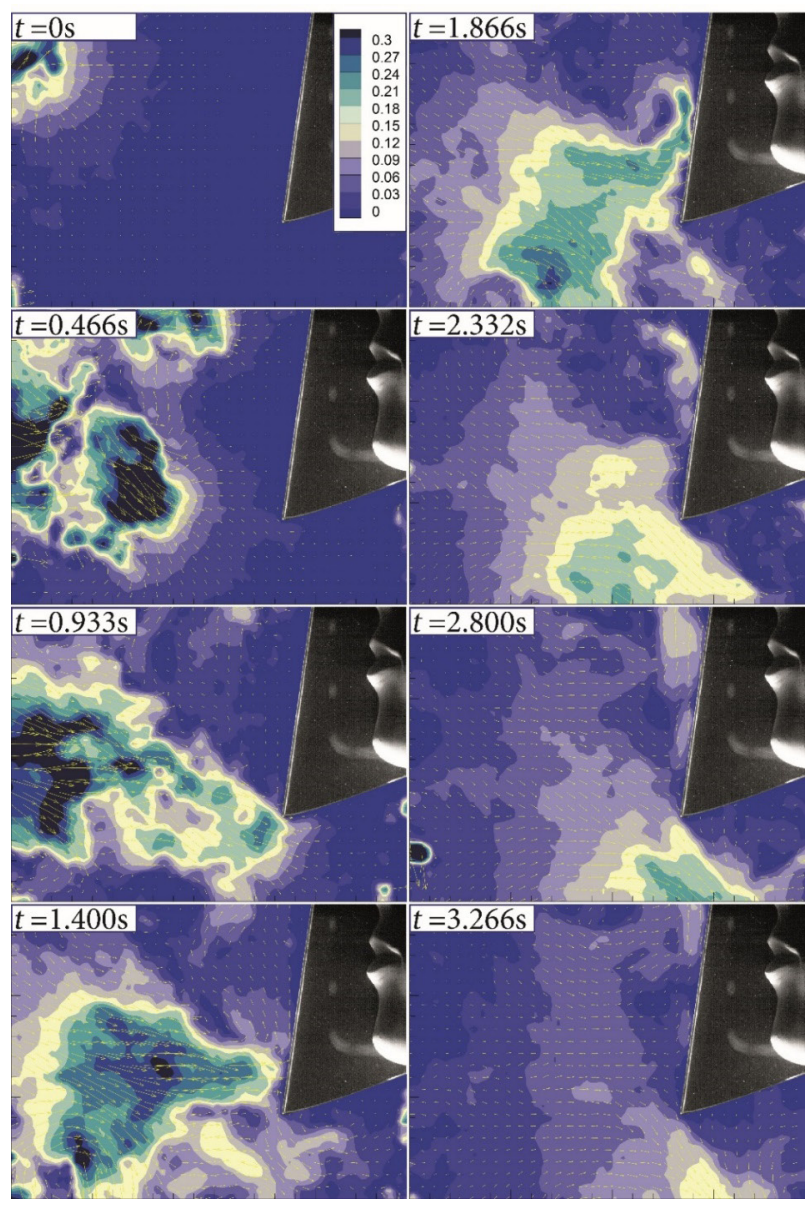

Figure 7. Snapshots of velocity vectors for the case where the mannequin is at an angle of $0^{\circ}$ from a distance of $L=50 \mathrm{~cm}$

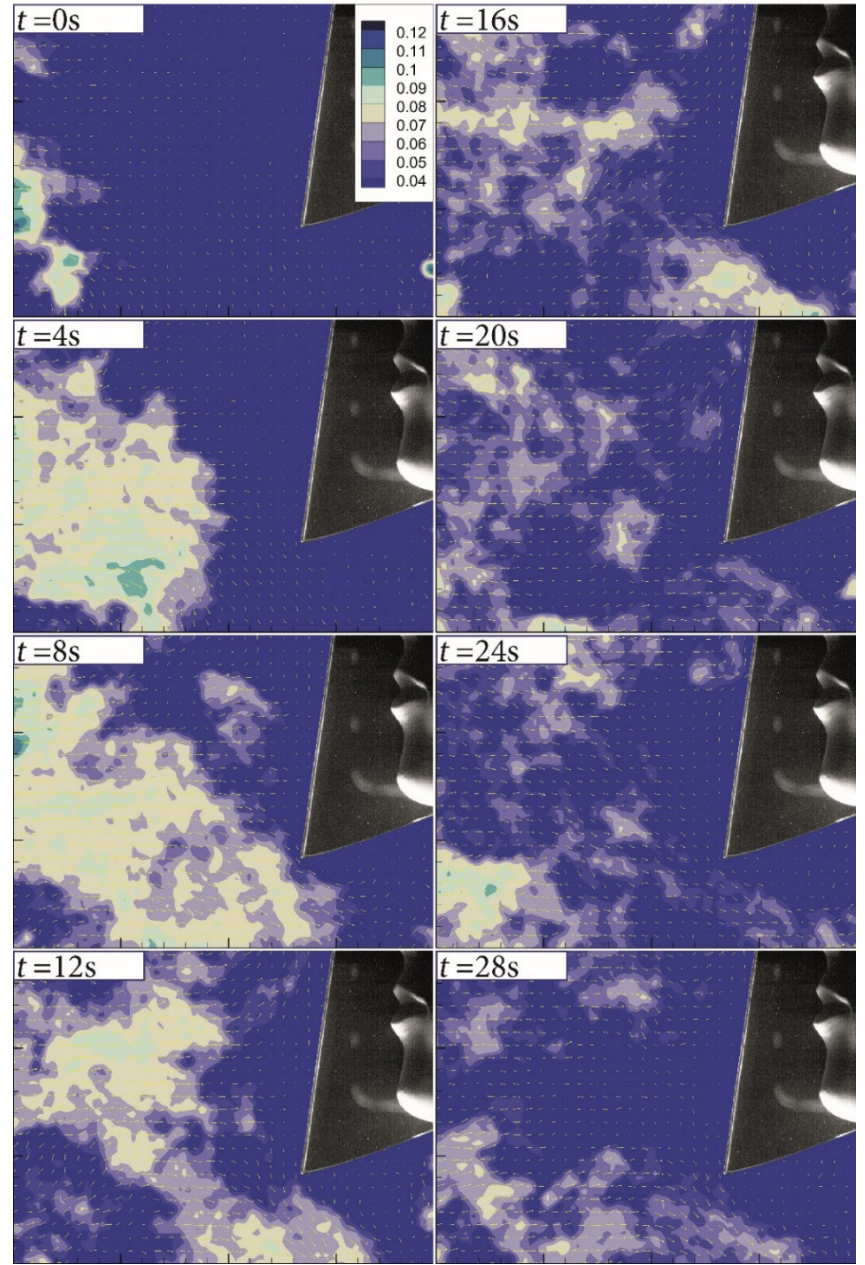

Figure 8. Snapshots of velocity vectors for the case where the mannequin is at an angle of $0^{\circ}$ from a distance of $L=150 \mathrm{~cm}$

velocity vectors coming to the surface of the mannequin moved away from the neck without reaching the face and jaw with the impact of the face shield. It will be seen more clearly when the snapshots taken at $\mathrm{t}=8,12$ and 16 seconds are examined.

Figure 9 displays the snapshots of the face shield surface taken flow simulation by positioning the mannequin at $\mathrm{L}=50 \mathrm{~cm}$ and at an angle of $10^{\circ}$. It did not take long for the fluid injected into the channel from the position of $\mathrm{L}=50 \mathrm{~cm}$ to reach the face shield as the two mannequins were close to each other, which preserved the energy emanating from the flow source and hit the shield surface intensely. Especially, the snapshots taken at $t=1.866 \mathrm{~s}$ and $t=2.232 \mathrm{~s}$ indicate that a vortex was formed due to the vectors hitting the shield surface at an angle of $10^{\circ}$ and the resulting vortex was in an orientation from the lower part of the shield to the jaw. Figure 10 presents the snapshots of the face mannequin positioned at $\mathrm{L}=150 \mathrm{~cm}$ away and an angle of $10^{\circ}$ to the flow. The fact that the time elapsed between the point where the flow simulation originated from the source and the point where it touched the face shield due to the distance caused the vectors to lose their energy. Although the vectors had a low velocity, they moved from the lower tip of the face shield to the jaw, especially between $t=16 \mathrm{~s}$ and $t=28 \mathrm{~s}$, due to the $10^{\circ}$ angle of the shield. In $t=20 \mathrm{~s}$, in particular, it is more clearly 


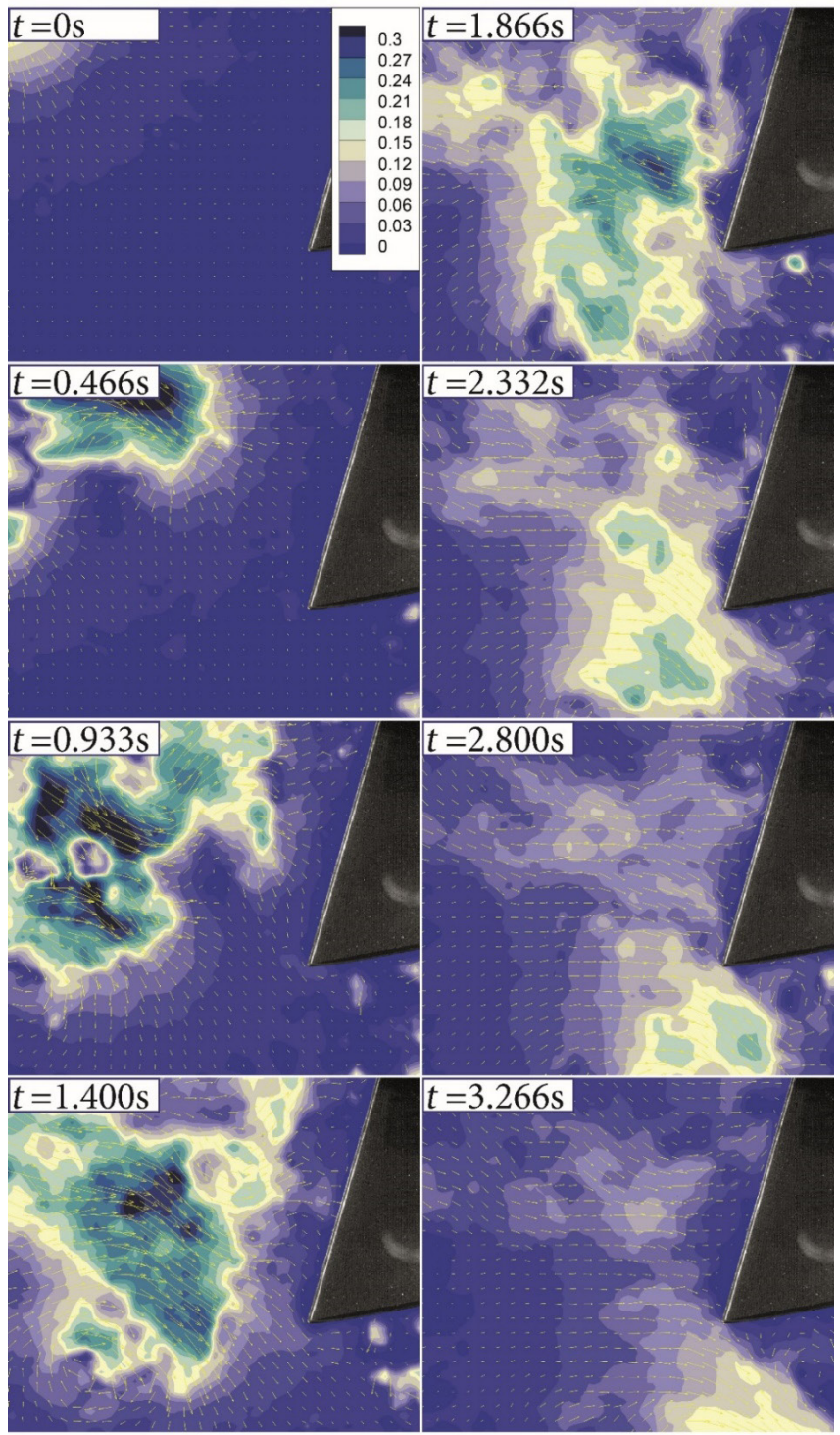

Figure 9. Snapshots of velocity vectors for the case where the mannequin is at an angle of $10^{\circ}$ from a distance of $L=50 \mathrm{~cm}$

seen that the velocity vectors were directed towards the jaw with the effect of the angle. Figures 11 and 12 contain Velocity Magnitude / Time graphs at the positions of $\mathrm{L}=50 \mathrm{~cm}-0^{\circ}$ and $\mathrm{L}=150 \mathrm{~cm}-0^{\circ}$, respectively. Time-dependent velocity change graphs were formed by putting points at different positions in the $\mathrm{Y}$ axis and the $\mathrm{X}$ axis in the field of view. $\mathrm{X}_{1}$ was created with the data obtained from the coordinates of $Y=60-X=40, X_{2}$ from the coordinates of $Y=60-X=80$, and $X_{3}$ from those of $Y=60-X=120$. Figure 11 and Figure 12 show that the vectors emerging from the source located $\mathrm{L}=50 \mathrm{~cm}$ away reach the face shield in a short time, while in a longer time when located $\mathrm{L}=150 \mathrm{~cm}$ away. The velocity data got dimensionless with dividing the velocity magnitude by source velocity. The graphs also indicate that the velocity of the vectors from $\mathrm{L}=50 \mathrm{~cm}$ away is approximately 10 times higher than that from $\mathrm{L}=150 \mathrm{~cm}$ away. In addition, the velocity of the vectors seems to decrease as a result of their movement towards the shield in the $\mathrm{X}$ axis over time. The flow loses its velocity as it moves away from the outlet source, and the $\mathrm{X}_{1}$ point close to the source has higher values than those acquired from the time-dependent velocity data taken from

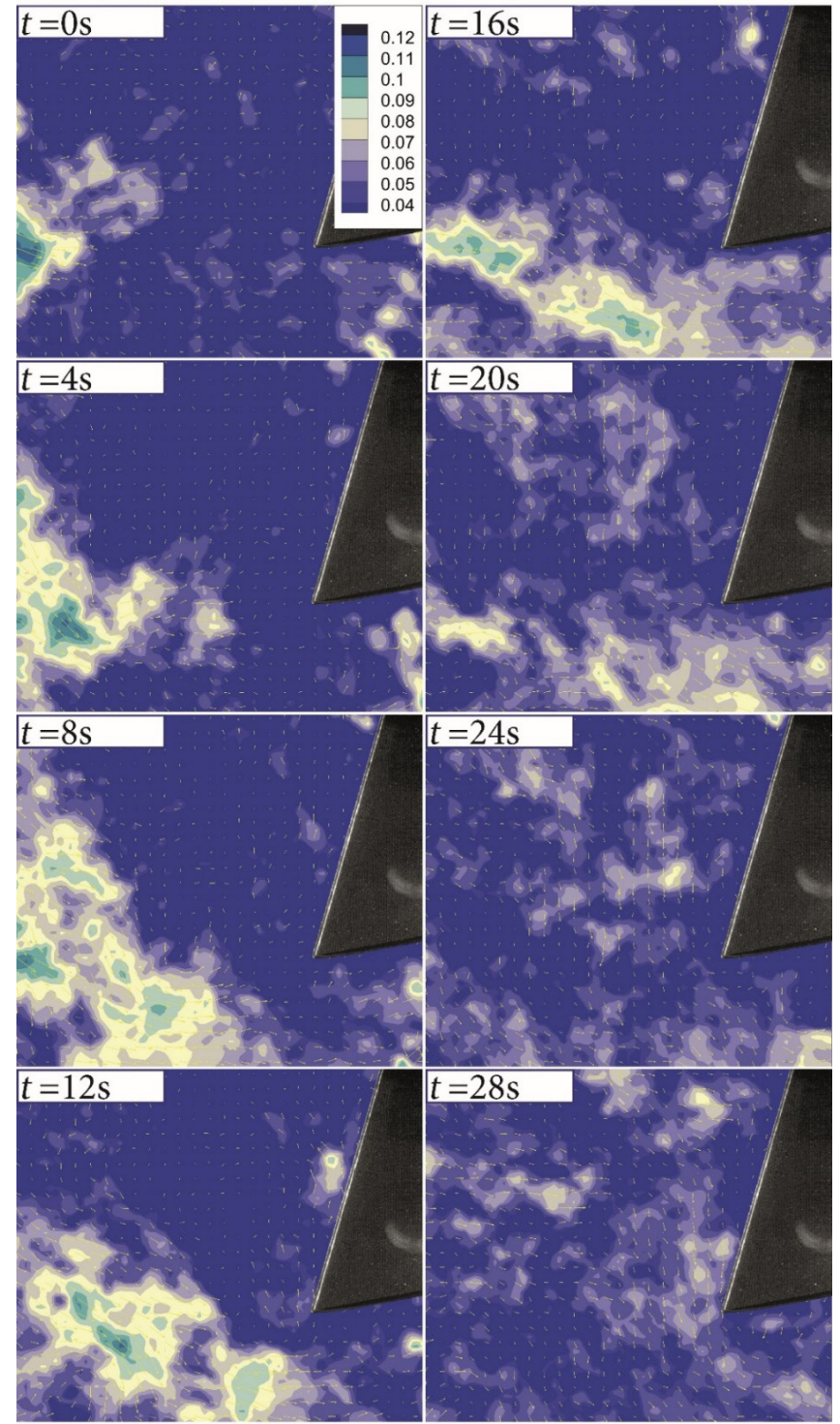

Figure 10. Snapshots of velocity vectors for the case where the mannequin is at an angle of $10^{\circ}$ from a distance of $L=150 \mathrm{~cm}$

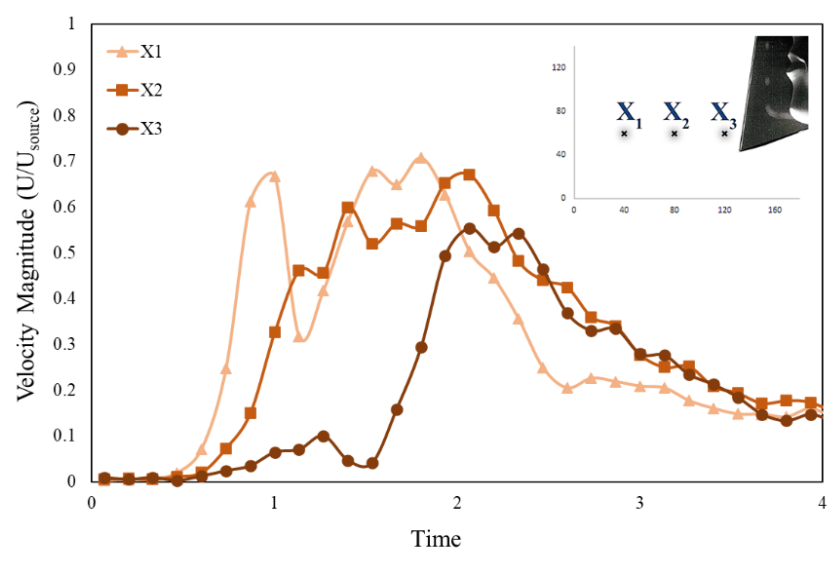

Figure 11. Time-dependent dimensionless velocity profiles taken from the positions $X=40 \mathrm{~mm}, X=80 \mathrm{~mm}$ and $X=120 \mathrm{~mm}$ in the flow direction from the fixed $Y$ axis at a distance of $L=50 \mathrm{~cm}$

the $\mathrm{X}_{2}$ and $\mathrm{X}_{3}$ points in both graphs. It is apparent how important the distance is between people and the way of using personal protective equipment with respect to the risk of direct exposure to infective droplets at first glance. However, 


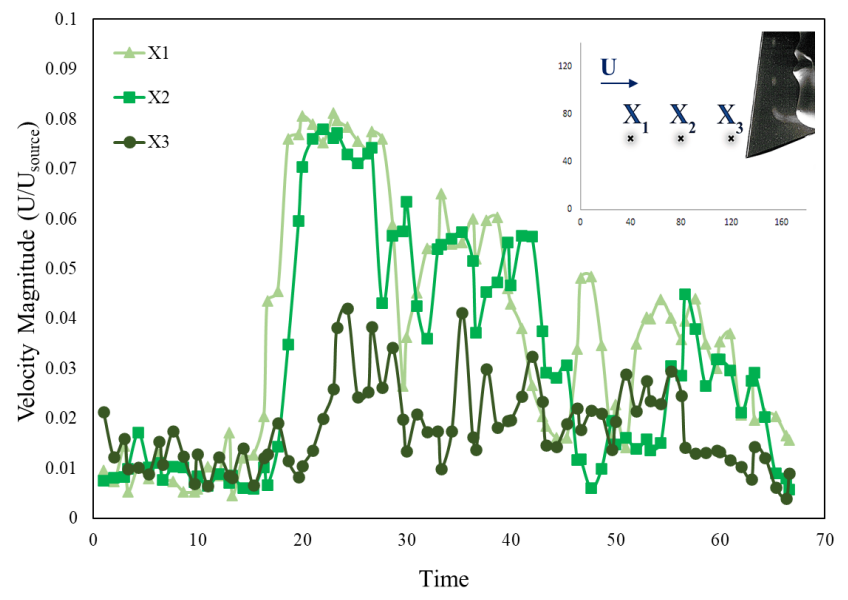

Figure 12. Time-dependent dimensionless velocity profiles taken from the positions $X=40 \mathrm{~mm}, X=80 \mathrm{~mm}$ and $X=120 \mathrm{~mm}$ in the flow direction from the fixed $Y$ axis at a distance of $L=150 \mathrm{~cm}$

it should be known that using PPE alone will not be enough. In this study, the flow structure around PPE exposed to a flow is examined.

\section{CONCLUSIONS}

The study conducted dye experiments and used the particle imaging velocity measurement (PIV) technique to determine the flow characteristics of the action of flow simulated from different distances $(\mathrm{L}=50 \mathrm{~cm}$ and $\mathrm{L}=150 \mathrm{~cm}$ ) placed in a channel in relation to the face shield positioned at different angles $\left(10^{\circ}\right.$ and $\left.0^{\circ}\right)$. In the results of study;

- In the experiment in which no face shields were used, the dye hitting the face directly moved towards the nose and eyes of the mannequin, whereas in the next experiment with a face shield, the shield caused to change direction of the flow in the first place and protected it away from the face and eyes.

- The experiment performed at a close distance ( $\mathrm{L}=50$ $\mathrm{cm} 0^{\circ}$ ) revealed that the face shield protected the face and eye area of the mannequin compared to the model without the face shield, but the flow was directed towards the neck region due to the energy of flow. The result of the experiment performed from a longer distance $(\mathrm{L}=150 \mathrm{~cm})$ demonstrated that the flow lost most of its energy as it approached the face shield and the flow hitting the shield surface moved away from the neck area without being directed to the jaw area.

- It was observed that the face shield prevented the contact of the vectors released at different speeds to the mannequin skins in the first place. However, the flow sent from $\mathrm{L}=50 \mathrm{~cm}$ and $\mathrm{L}=150 \mathrm{~cm}$ away from the face shield positioned at an angle of $10^{\circ}$ was directed towards the jaw area due to the vortex formed in the lower part of the shield.

As a result of this work, it has been shown that the risk of direct exposure to velocity vectors (infective droplets) at first glance, the distance between people as well as the way of using the personal protective equipment and their characteristics are of great importance for health. Additionally, this study has shown that exposure to the air flow released as a result of speech at a close distance is a health risk even if protective equipment is used, and the distance between people should be maintained under all conditions.

The study of the flow characteristic on the face shield, which is a personal protective equipment, aimed to reveal the conditions of the object under the flow. From the results obtained, it is clearly seen that protection is insufficient in face shields so long as jaw, upper forehead and side gaps are not covered since the face shields appear to be very sensitive to the up/down movement of the head. It is recommended that a surgical mask should be used together with a face shield against the possibility of particles entering the respiratory tract from the gaps on the sides and under the jaw especially in such types of face shields.

\section{ACKNOWLEDGEMENT}

We would like to express our deepest regards and thanks to the healthcare professionals in Turkey and all around the world, who work very hard in these difficult times.

We are also very grateful to the reviewers for their valuable comments, which have been utilized to improve the quality of the paper.

\section{REFERENCES}

[1] Correia, G., Rodrigues L., Gameiro da Silva, M., Gonçalves, T. (2020). Airborne route and bad use of ventilation systems as non-negligible factors in SARS-CoV-2 transmission. Med Hypotheses; 141:109781. https://doi.org/10.1016/j.mehy.2020.109781.

[2] Segredo-Otero, E., Sanjuán, R. (2019). The effect of genetic complementation on the fitness and diversity of viruses spreading as collective infectious units. Virus Res; 267:41-8. https://doi.org/10.1016/j. virusres.2019.05.005.

[3] Pan, M., Lednicky, J.A., Wu, C.Y. (2019). Collection, particle sizing and detection of airborne viruses. J Appl Microbiol; 127:1596-611. https://doi.org/10.1111/jam.14278.

[4] Chen, C., Lin, C.H., Jiang, Z., Chen, Q. (2014). Simplified models for exhaled airflow from a cough with the mouth covered. Indoor Air, 24:580-91. https://doi.org/10.1111/ina.12109.

[5] Wang, J., Chow, T.T. (2011) Numerical investigation of influence of human walking on dispersion and deposition of expiratory droplets in airborne infection isolation room. Build Environ; 46:1993-2002. https://doi.org/10.1016/j.buildenv.2011.04.008.

[6] Li, X., Inthavong, K., Tu, J. (2012). Particle inhalation and deposition in a human nasal cavity from the external surrounding environment. Build Environ; 47:32-9. https://doi.org/10.1016/j.buildenv.2011.04.032.

[7] Nishimura, H., Sakata, S., Kaga, A. (2013). A new methodology for studying dynamics of aerosol particles in sneeze and cough using a digital high-vision, high-speed video system and vector analyses. PLoS One; 8. https://doi.org/10.1371/journal.pone.0080244.

[8] Tang, J. W., Noakes, C. J., Nielsen, P. V., Eames, I., Nicolle, A., Li, Y., \& Settles, G. S. (2011). Observing and quantifying airflows in the infection control of aerosol-and airborne-transmitted diseases: an over- 
view of approaches. Journal of Hospital Infection, 77(3), 213-222.

[9] Berlanga FA, de Adana MR, Olmedo I, Villafruela JM, San José JF, Castro F. (2018). Experimental evaluation of thermal comfort, ventilation performance indices and exposure to airborne contaminant in an airborne infection isolation room equipped with a displacement air distribution system. Energy Build; 158:209-21. https://doi. org/10.1016/j.enbuild.2017.09.100.

[10] Thierry, B., Célérier, C., Simon, F., Lacroix, C., Khonsari, R.H. (2020). How and why use the EasyBreath ${ }^{\circ}$ Decathlon surface snorkeling mask as a personal protective equipment during the COVID-19 pandemic? Eur Ann Otorhinolaryngol Head Neck Dis: 5-7. https:// doi.org/10.1016/j.anorl.2020.05.006.

[11] King, M.F., Noakes, C.J., Sleigh, P.A. (2015) Modeling environmental contamination in hospital single- and four-bed rooms. Indoor Air; 25:694-707. https://doi.org/10.1111/ina.12186.

[12] Vordos, N., Gkika, D.A., Maliaris, G., Tilkeridis, K.E., Antoniou, A., Bandekas, D. V., et al. (2020) How 3D printing and social media tackles the PPE shortage during Covid - 19 pandemic. Saf Sci; 1 30:104870. https://doi.org/10.1016/j.ssci.2020.104870.

[13] Vuorinen, V., Aarnio, M., Alava, M., Alopaeus, V., Atanasova, N., Auvinen, M., et al. (2020) Modelling aerosol transport and virus exposure with numerical simulations in relation to SARS-CoV-2 transmission by inhalation indoors. Saf Sci; 130:104866. https://doi. org/10.1016/j.ssci.2020.104866.

[14] Davis, P.J., Spady, D., Forgie, SED. (2007) A survey of Alberta physicians' use of and attitudes toward face masks and face shields in the operating room setting. Am J Infect Control; 35:455-9. https://doi. org/10.1016/j.ajic.2006.08.011

[15] Boškoski, I., Gallo, C., Wallace, M. B., \& Costamagna, G. (2020). COVID-19 pandemic and personal protective equipment shortage: protective efficacy comparing masks and scientific methods for respirator reuse. Gastrointestinal endoscopy, 92(3), 519-523.

[16] Sapoval, M., Gaultier, A. L., Del Giudice, C., Pellerin, O., Kassis-Chikhani, N., Lemarteleur, V., ... \& Attal, J. P. (2020). 3D-printed face protective shield in interventional radiology: Evaluation of an immediate solution in the era of COVID-19 pandemic. Diagnostic and interventional imaging, 101(6), 413-415.

[17] Shokrani, A., Loukaides, E.G., Elias, E., Lunt, A.J.G. (2020). Exploration of alternative supply chains and distributed manufacturing in response to COVID-19; a case study of medical face shields. Mater Des, 192:108749. https://doi.org/10.1016/j.matdes.2020.108749.

[18] Skamnelos, A., Murino, A., Lazaridis, N., Cunado, L., \& Despott, E. J. (2020). Endoscopy during the COVID-19 pandemic: simple construction of a single-use, disposable face shield using inexpensive and readily available materials. VideoGIE, 5(9), 399-401.

[19] Zhou, Q., Qian, H., Ren, H., Li, Y., \& Nielsen, P. V. (2017). The lock-up phenomenon of exhaled flow in a stable thermally-stratified indoor environment. Building and Environment, 116, 246-256.

[20] Dbouk, T., \& Drikakis, D. (2020). On coughing and airborne droplet transmission to humans. Physics of Fluids, 32(5), 053310.

[21] Licina, D., Pantelic, J., Melikov, A., Sekhar, C., \& Tham, K. W. (2014). Experimental investigation of the human convective boundary layer in a quiescent indoor environment. Building and Environment, 75, 79-91.

[22] Badeau, A., Afshari, A., Goldsmith, T., Frazer, D. (2002) Preliminary prediction of flow and particulate concentration produced from normal human cough dispersion. Annu Int Conf IEEE Eng Med Biol - Proc; 1:246-7. https://doi.org/10.1109/iembs.2002.1134475.
[23] Ge, Q., Li, X., Inthavong, K., Tu, J. (2013). Numerical study of the effects of human body heat on particle transport and inhalation in indoor environment. Build Environ, 59:1-9. https://doi.org/10.1016/j. buildenv.2012.08.002.

[24] Richmond-Bryant, J. (2009). Transport of exhaled particulate matter in airborne infection isolation rooms. Build Environ, 44:44-55. https://doi.org/10.1016/j.buildenv.2008.01.009.

[25] Tang, J.W., Nicolle, A.D., Klettner, C.A., Pantelic, J., Wang, L., Suhaimi, A. Bin, et al. (2013). Airflow Dynamics of Human Jets: Sneezing and Breathing - Potential Sources of Infectious Aerosols. PLoS One; 8:17. https://doi.org/10.1371/journal.pone.0059970.

[26] Clark, R. P., \& de Calcina-Goff, M. L. (2009). Some aspects of the airborne transmission of infection. Journal of the Royal Society Interface, 6(suppl_6), S767-S782.

[27] Ozalp, C., Pinarbasi, A. H. M. E. T., \& Sahin, B. (2010). Experimental measurement of flow past cavities of different shapes. Experimental Thermal and Fluid Science, 34(5), 505-515. https://doi. org/10.1016/j.expthermflusci.2009.11.003.

[28] Alnak, D.E., Varol, Y., Firat, M., Oztop, H.F., Ozalp, C. (2019). Experimental and numerical investigation of impinged water jet effects on heated cylinders for convective heat transfer. Int I Therm Sci; 135:493-508. https://doi.org/10.1016/j.ijthermalsci.2018.09.037.

[29] Gupta, J.K., Lin, C.H., Chen, Q. (2010). Characterizing exhaled airflow from breathing and talking. Indoor Air, 20:31-9. https://doi. org/10.1111/j.1600-0668.2009.00623.x.

[30] Chao, C. Y. H., Wan, M. P., Morawska, L., Johnson, G. R., Ristovski, Z. D., Hargreaves, M., ... \& Katoshevski, D. (2009). Characterization of expiration air jets and droplet size distributions immediately at the mouth opening. Journal of aerosol science, 40(2), 122-133.

[31] Özalp, C., Polat, C., Saydam, D., Söyler, M. (2020). Dye Injection Flow Visualization Around a Rotating Circular Cylinder . European Mechanical Science , 4 (4) , 185-189 . doi: https://doi.org/10.26701/ ems.794683 